\title{
Symmorphosis in the proximal pathway for oxygen in the leaf-eared mouse Phyllotis darwini
}

\author{
MAURICIO CANALS ${ }^{1}$, DANIELA FIGUEROA ${ }^{1}$ and PABLO SABAT S $^{1,2}$
}

\author{
${ }^{1}$ Departamento de Ciencias Ecológicas, Facultad de Ciencias, Universidad de Chile, Casilla 653, Santiago- \\ Chile.e-mail: mcanals@uchile.cl \\ ${ }^{2}$ Center for Advanced Studies in Ecology \& Biodiversity and Departamento de Ciencias Ecológicas, Facultad \\ de Ciencias, Universidad de Chile, Casilla 653, Santiago-Chile, e-mail: psabat@uchile.cl
}

\begin{abstract}
In this report, we explore the matching of structures to functional needs by comparing previously reported data of maximal oxygen consumption and the development of the lung in the leaf-eared mouse Phyllotis darwini in warm and cold environments. We discuss whether the state of structural design is commensurate with functional needs from regulated morphogenesis as predicted by the hypothesis of symmorphosis. We found a close match between respiratory structures and functional needs during postnatal development, expressed as safety factors close to unity. However, in the adult stage the safety factors were greater than two, which suggests that adult animals acquired a structure greater than that required considering their maximum capacities. A high safety factor in the respiratory system of adult mice may be a consequence of the symmorphosis that operates during ontogeny and does not necessarily support a rejection of this hypothesis.
\end{abstract}

Key terms: Metabolism, Ontogeny, Phyllotis darwini, Symmorphosis

\section{INTRODUCTION}

Persistence and reproduction of animals depends upon energy acquisition, absorption, transformation, allocation and expenditure, all factors that are intrinsically limited by the design of the organism, probably in the context of extrinsic limitations, such as food availability (Karasov, 1986; Weiner, 1992; Speakman, 2000; Bacigalupe and Bozinovic, 2002). Regarding only physiological constraints, there are three principal hypotheses that attempt to explain physiological limitation of energy budgets: i) shared central machinery limits the sustained metabolic rate ("central limitation hypothesis"); ii) energy consuming machinery limits the sustained metabolic rate ("peripheral limitation hypothesis"); and iii) the capacity of the central machinery closely matches that of the peripheral tissues and energy requirements (Bacigalupe and Bozinovic,
2002). The first hypothesis implies that metabolic limits are independent of the manner of energy expenditure and peripheral organs always possess an excess capacity. The second hypothesis proposes that central organs have excess capacity. The third hypothesis proposes that organisms do not have excess capacities, but rather the capacity of central organs to supply energy matches the expenditure capacity of peripheral organs, just as proposed by the symmorphosis hypothesis (Taylor and Weibel, 1981).

Symmorphosis is defined as "a state of structural design commensurate with functional needs resulting from regulated morphogenesis, whereby the formation of structural elements is regulated to satisfy but not exceed the requirements of the functional system" (Taylor and Weibel, 1981). Thus the symmorphosis hypothesis proposes that if matching structures to functional needs were combined with the 
strict economy of energy and materials, the result would be an optimal organ design for the specific function it serves (Weibel et al. 1991, 1992). This hypothesis contains three predictions: i) organism design will be optimized; ii) if the design is optimized in the sense of material economy, then structure is the key factor in determining maximal organ capacities, and adjustments to it require morphogenetic processes; and iii) if prediction ii) operates in each intermediate step of the whole function of an organ, each step contributes to the limitation of the whole function (Jones, 1998; Weibel, 1998; Canals, 2002).

Although symmorphosis was first proposed for the oxygen pathway in mammals, it has been established as a general hypothesis of economic design (Weibel at al., 1998). The oxygen pathway was considered a good model for two reasons. First, it involves a series of linked structures in which the effect of the structural parameters on functional capacity can be defined. For example, $V_{\mathrm{O} 2}=\left(\Delta \mathrm{PO}_{2}\right)$ - $D_{\mathrm{LO} 2}$ (Bohr's equation), where $V_{\mathrm{O} 2}$ is oxygen consumption, $\Delta \mathrm{PO}_{2}$ is the alveoluscapillary pressure gradient, and $\mathrm{D}_{\mathrm{LO} 2}$ is the oxygen diffusion capacity or oxygen conductance. The latter depends directly on the alveolar and capillary surface, hematocrit and capillary volume, and inversely on the thickness of the alveoluscapillary barrier (Weibel et al., 1991). The second reason is that the overall function has a measurable upper limit, maximal oxygen consumption $\mathrm{V}_{\mathrm{O} 2 \max }$ (Weibel, 1998).

The symmorphosis hypothesis has generated great debate that remains unresolved. Evidence in favor of symmorphosis is as abundant as evidence against it (Bacigalupe and Bozinovic, 2002; Canals 2002). Regarding the oxygen pathway, Weibel et al (1992) found that mithocondrial volume, cardiac output and capillary volume varied with body mass with the same allometric exponent as maximal oxygen consumption, suggesting that mithochondria achieve the same rate of oxidative phosphorylation in all mammals, supporting the symmorphosis hypothesis (Weibel et al., 1991; 1992). However, the same authors reported that in the lung, the oxygen diffusion capacity did not adjust to functional needs, with the result that species of large body size have an excess capacity relative to that of small species (Weibel, 1998). Jones (1998) also reported an excess oxygen diffusion capacity in well-trained equines.

The original approach of Weibel et al. (1981) was comparison between species, using animals of the same body mass adapted to environments with different energetic requirements (adaptive variation) and animals of different body masses in which the scaling of maximal capacities should be paralleled by structure (allometric variation). However, the concept of symmorphosis may be evaluated within particular species, using a similar protocol (Bacigalupe and Bozinovic, 2002).

In this report we explore matching structures to functional needs by comparing previously reported data of maximal oxygen consumption and the development of the lung in the leaf-eared mouse Phyllotis darwini in warm and cold environments. We discuss whether the state of structural design is commensurate with functional needs from regulated morphogenesis as predicted by the symmorphosis hypothesis (i.e. at the upper limit of the overall function of the respiratory system, the maximum metabolic rate should be paralleled by structural changes) (Weibel et al., 1991; 1992; Seymour et al., 2004; 2005; Runciman et al., 2005; Canals et al., 2005; Figueroa et al., 2007; Canals et al., 2007).

\section{SAMPLE AND METHODS}

Fifteen adult males $(\mathrm{Mb}=54.4 \pm 17.3 \mathrm{~g})$ and 15 adult females $(\mathrm{Mb}=37.7 \pm 7.6 \mathrm{~g})$ of Phillotis darwini were trapped in Quebrada de la Plata (coordenadas). The animals were transported to the laboratory, where they were kept in pairs at room temperature with food (sunflower seeds and Champion ${ }^{\mathrm{R}}$ rabbit food) and water ad lib. After mating, pregnant females were maintained in individual cages $(40 \times 40 \times 20 \mathrm{cms})$ in climatic chambers and randomly assigned 
to one of two temperature treatments. One group was maintained at low energetic requirements for thermoregulation at a constant temperature of $30 \pm 2^{\circ} \mathrm{C}$ (warm acclimated group) and a second group maintained at high energetic requirements for thermoregulation, $15 \pm 2^{\circ} \mathrm{C}$ (coldacclimated group), about $10^{\circ} \mathrm{C}$ below the lower limit of thermoneutrality for this species (Bozinovic et al., 1988). After the offspring were born, three or four unrelated individuals were selected for each environmental condition at days: 1 (neonates), 7, 14, 21 and 60 (adult).

The lung volume, the alveolar surface density and the thickness of the alveoluscapillary barrier were measured by means of water displacement and the stereological method in optical and electronic transmission microscopy, respectively.

From these structural measurements, the morphometric oxygen diffusion capacity (tissue) was estimated using

$$
D_{t} O_{2}=\kappa \frac{A S_{d} \cdot V p}{\tau_{h}},
$$

where $\mathrm{D}_{\mathrm{t}} \mathrm{O}_{2}$ is the oxygen diffusion capacity of the alveolo-capillary barrier (tissue) and $\kappa$ is Krogh's diffusion coefficient $\kappa=4.1$. $10^{-10} \mathrm{~cm}^{2} \mathrm{~s}^{-1} \mathrm{mbar}^{-1}=4.1 \cdot 10^{-12} \mathrm{~cm}^{2} \cdot \mathrm{s}^{-1}$. $\mathrm{Pa}^{-1}$ (Gehr et al., 1981). $\mathrm{AS}_{\mathrm{d}}$ is the alveolar surface density, $\mathrm{Vp}$ is the parenchymal lung volume and $\tau_{\mathrm{h}}$ is the harmonic mean thickness of the blood-gas barrier. The total air-erythrocyte oxygen diffusion capacity was estimated with $D_{L} O_{2} \approx D_{t} O_{2} / 10$, a reasonable estimator derived from the ratio $\mathrm{D}_{\mathrm{L}} \mathrm{O}_{2} / \mathrm{D}_{\mathrm{t}} \mathrm{O}_{2}$ (Canals et al., 2005).

In all animals maximal oxygen consumption was determined in an openflow respirometer system (Sable Systems). All measurements were made during the resting phase ( 8 to 18: 00 hours) of the species. Using the oxygen conductance and maximal oxygen consumption during ontogeny reported by Canals et al. (2009a;b), we estimated the gradients of partial pressure between air and blood $\left(\triangle \mathrm{PO}_{2}\right)$ necessary to sustain the maximum metabolism of each animal from $\triangle \mathrm{PO}_{2}=$ $V \mathrm{O}_{2 \max } / \mathrm{D}_{L} \mathrm{O}_{2}$. Because the usual values of $\Delta \mathrm{PO}_{2}$ in mammals are around $7.5 \mathrm{kPa}$ or 60 $\mathrm{mmHg}$, the ratio between this value and that necessary to satisfy maximum oxygen consumption was used as a crude estimate of the safety factor associated with oxygen diffusion. We used a non-parametric ANOVA to estimate safety factors. Other methodological details are reported in the cited articles (Canals et al., 2009 a;b)

\section{RESULTS}

The gradients of partial pressure between air and blood $\left(\Delta \mathrm{PO}_{2}\right)$ necessary to sustain the maximum metabolism of each animal were close to the usual values in young mammals $(7.5 \mathrm{kPa}$ or $60 \mathrm{mmHg}$ ), but in adults $\Delta \mathrm{PO}_{2}$ needs were lower (Table 1 ), The ratio between this value and the value necessary to satisfy maximum oxygen consumption provides a crude estimate of the safety factor (Sf) associated with oxygen diffusion. Estimated safety factors of young individuals of both groups were very close to unity; and in one group it fell below one. This suggests that the respiratory system design is strictly linked to maximum capacities during ontogeny, as suggested by symmorphosis. Safety factors were not affected by the acclimation temperature $\left(\mathrm{F}_{1,21}=1.002, \mathrm{p}=0.328\right)$. However, we found differences among age groups $\left(\mathrm{F}_{4,21}=3.13, \mathrm{p}=0.036\right)$. Multiple comparisons revealed that safety factors of adults were different from those of all other groups, while other groups did not show significant differences (Table 1, Figure 1).

\section{DISCUSSION}

From an evolutionary point of view, several objections have been proposed to symmorphosis. For example, i) organisms perform different functions, not just one; consequently constraints are pervasive from reaching a single optimal solution; ii) biological materials have limitations related to their own histories; iii) energetic efficiency is not necessarily what selection maximizes; iv) environments are always changing and selection cannot follow the rhythm of that change; and vi) genetic drift operates in all populations and can be an 
important factor in determining the phenotype (Garland, 1998; Bacigalupe and Bozinovic, 2002).

The authors who proposed the symmorphosis hypothesis were surprised when they observed that the diffusing capacity of the lung was only partly adjusted to maximal oxygen capacity both in adaptative and allometric variation (Taylor and Weibel, 1981; Weibel et al., 1991; 1992), so species of great body size had excess diffusing capacity, whereas smaller species did not. For example, while the safety factors of small animals are small, they can reach values as high as 6 in some artiodactyls of large size (Table 2). Safety factors of other biological structures vary between 1 and 10, most of them being between 1.3 and 6 (Diamond, 1988). Alexander (1998) proposed that the presence of safety factors contradicts the material economy proposed in the hypothesis of symmorphosis, but is consistent with optimization of organs and organisms whether the role of natural selection is incorporated. A safety factor with both low energetic cost and minimum fail probability would be favored by natural selection (Alexander, 1998). The same author showed theoretically that in a system composed of a chain of organs, the probability of failure of the entire chain can be minimized by i) increasing the value of the safety factor of a particular organ instead of another and ii) increasing the value of the safety factor of the organ with lowest predictability (Alexander, 1997).

Thus the symmorphosis hypothesis is questioned in its economy of design aspect. However there is abundant evidence in favor of symmorphosis (Taylor et al., 1996; Weibel et al., 1996; Chappel et al., 1999; Hammond et al., 2000; Seymour et al. 2004; 2005; Runciman et al., 2005).

The advanced results during the ontogeny of $P$. darwini agree the symmorphosis hypothesis, in a similar way that do the studies of Seymour et al. (2004, 2005) and Runciman et al. (2005) in birds They found that altricial pelicans and precocial turkeys have a parallel allometry between $\mathrm{VO}_{2 \max }$ and $\mathrm{DLO}_{2}$, consistent with the concept of Symmorphosis during development. The variability found in $\mathrm{VO}_{2 \max }$ and $\mathrm{DLO}_{2}$ was attributable to age differences between the experimental groups, but there is some residual variability attributable to individual or possible sex differences among individuals. While the latter variable was not controlled,

TABLE 1

Mass specific oxygen diffusion capacity $\left(\mathrm{D}_{\mathrm{L}} \mathrm{O}_{2} / \mathrm{m}_{\mathrm{b}}\right)$ maximum metabolic rate $\left(V \mathrm{O}_{2 \max }\right)$

(from Canals et al.2009a,b), required alveolo-capillary gradient of partial oxygen pressures $\left(\triangle \mathrm{PO}_{2}=V \mathrm{O}_{2 \max } / \mathrm{D}_{L} \mathrm{O}_{2}\right)$ and safety factor $\left(\mathrm{Sf}=7.5 \mathrm{kPa} / \Delta \mathrm{PO} \mathrm{O}_{2}\right)$ in individuals of different ages of Phyllotis darwini acclimated to two environmental temperatures, $15^{\circ}$ and

$30^{\circ} \mathrm{C}$ from gestation). Values expressed as average \pm 1 standard deviation.Asterisks denote significant differences among groups after the posteriori Tukey test.

\begin{tabular}{lccccc}
\hline Age & $\mathrm{T}$ & $\mathrm{D}_{\mathrm{L}} \mathrm{O}_{2} / \mathrm{m}_{\mathrm{b}}\left(\mathrm{mlO}_{2} \mathrm{~s}^{-1} \mathrm{~Pa}^{-1} \mathrm{~g}^{-1}\right) \times 10^{-7}$ & $V O_{2 \max }\left(\mathrm{mlO}_{2} \mathrm{~g}^{-1} \mathrm{~h}^{-1}\right)$ & $\Delta \mathrm{PO}_{2}(\mathrm{kPa})$ & $\mathrm{SF}$ \\
\hline 1 & 30 & $2.66 \pm 1.48$ & $5.02 \pm 0.53$ & $6.74 \pm 3.65$ & $1.4 \pm 0.7$ \\
7 & 30 & $2.74 \pm 1.73$ & $4.84 \pm 0.98$ & $7.41 \pm 6.46$ & $1.7 \pm 1.3$ \\
14 & 30 & $5.20 \pm 2.37$ & $13.43 \pm 1.67$ & $8.39 \pm 3.99$ & $1.0 \pm 0.4$ \\
21 & 30 & $3.89 \pm 0.48$ & $11.14 \pm 2.79$ & $8.11 \pm 2.50$ & $1.0 \pm 0.4$ \\
60 & 30 & $6.99 \pm 3.29$ & $7.07 \pm 1.14$ & $3.06 \pm 0.79$ & $2.6 \pm 0.8^{*}$ \\
1 & 15 & $3.48 \pm 2.77$ & $6.47 \pm 1.54$ & $8.51 \pm 6.67$ & $1.7 \pm 1.8$ \\
7 & 15 & $3.01 \pm 1.35$ & $7.39 \pm 1.12$ & $8.13 \pm 4.43$ & $1.2 \pm 0.7$ \\
14 & 15 & $2.86 \pm 0.56$ & $13.86 \pm 3.38$ & $13.83 \pm 3.92$ & $0.6 \pm 0.2$ \\
21 & 15 & $4.68 \pm 1.24$ & $11.50 \pm 3.74$ & $6.81 \pm 1.65$ & $1.1 \pm 0.3$ \\
60 & 15 & $6.20 \pm 2.12$ & $8.14 \pm 1.19$ & $4.04 \pm 1.76$ & $2.2 \pm 1.1^{*}$ \\
\hline
\end{tabular}


analyses suggest that sex is not an important variable (Takezawa et al., 1980, but see Hammond et al., 2000 for an example in fowls).

Our results also showed that in the adult stage the safety factors were greater than 2 , which suggests that in this stage animals developed a structure greater than that required by the maximum capacities (see also Gehr et al., 1981; Taylor and Weibel 1981; Taylor et al., 1996; Weibel et al., 1991; 1992 for studies in other mammal species). On the basis of Bohr's equation, comparisons between animals of different size are justified; since $\mathrm{D}_{\mathrm{L}} \mathrm{O}_{2}$ should be proportional to $\mathrm{VO}_{2 \max }$ based on the strong assumption that $\Delta \mathrm{PO}_{2}$ is independent of body size. When this is not the case, larger animals may have lower $\Delta \mathrm{PO}_{2}$ than smaller animals, and then the safety factor in adults could be overestimated. However there is no empirical evidence to support that $\triangle \mathrm{PO} 2$ varies with body mass (Weibel, 1983).

Our results are consistent with an excess of $\mathrm{D}_{\mathrm{L}} \mathrm{O}_{2}$ in adults because during postnatal development there is a stage of high energetic requirements that necessarily implies a large refinement of respiratory capacities, leading to a full adjustment between structure and maximal capacity (i.e. a safety factor close to unity). But this refinement is maintained consistently in both experimental groups $\left(15^{\circ} \mathrm{C}\right.$ and $\left.30^{\circ} \mathrm{C}\right)$ in the adult age, in spite of a decrease in energetic requirements per unit of mass. This phenomenon results in an excess of structure which constitutes a safety factor that appears to protect $P$. darwini from the transient challenges of highly energetic environmental demands. In this sense, a high safety factor in the respiratory system of adults could be a consequence of the symmorphosis that operates during ontogeny and does not provide support to a rejection of this hypothesis. This result suggests that symmorphosis should always be tested during organism development, in which structural design may be commensurate with functional needs from regulated morphogenesis.

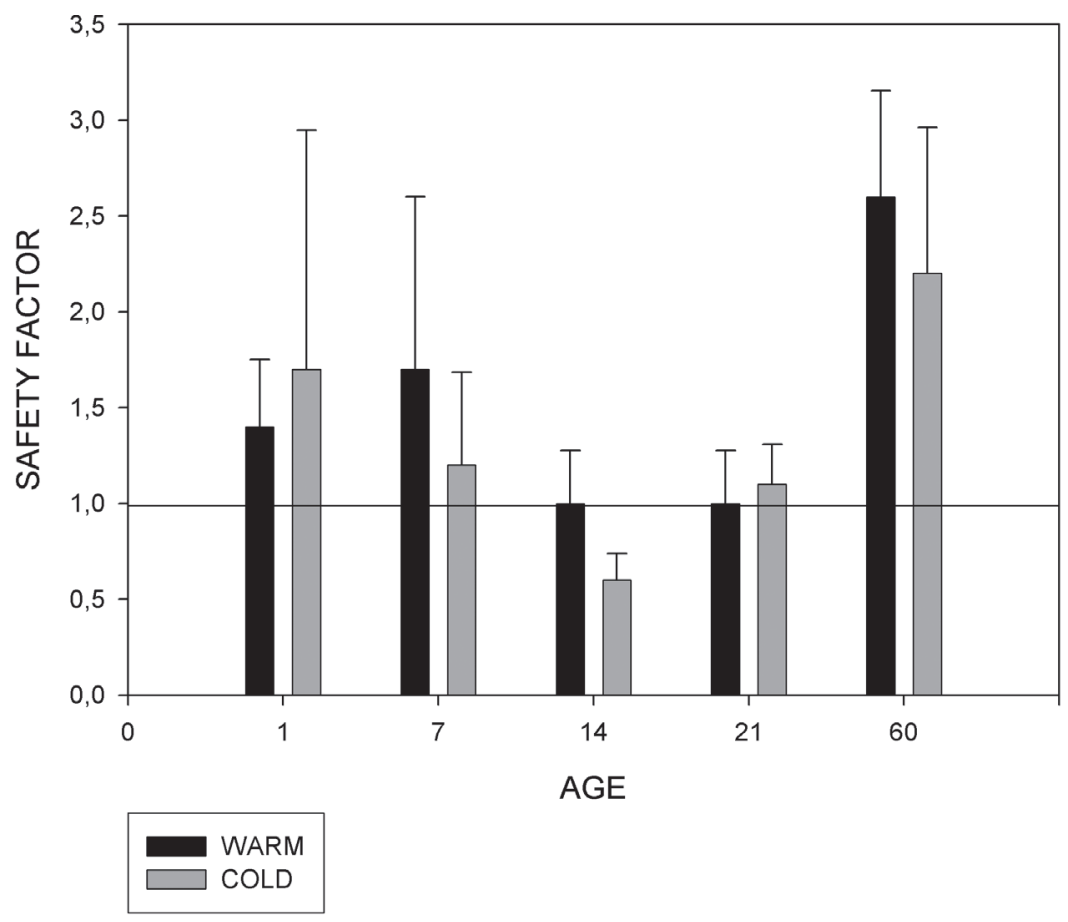

Figure 1: Estimated safety factor of lungs in Phyllotis darwini during development at two environmental temperatures, $15^{\circ}$ (cold) and $30^{\circ} \mathrm{C}$ (warm). The solid line represents a perfect adjustment of morphometric oxygen diffusion capacity to the maximal oxygen consumption for a usual alveolus-capillary gradient of partial oxygen pressures $(7.5 \mathrm{kPa})$. 
TABLE 2

Mass specific oxygen diffusion capacity $\left(\mathrm{D}_{\mathrm{L}} \mathrm{O}_{2} / \mathrm{m}_{\mathrm{b}}\right)$ maximum metabolic rate $\left(V \mathrm{O}_{2 \max }\right)$, required alveolo-capillary gradient of partial oxygen pressures $\left(\triangle P O_{2}=V O_{2 \max } / D_{L} O_{2}\right)$ and safety factor $\left(\mathrm{SF}=7.5 \mathrm{kPa} / \Delta \mathrm{PO}_{2}\right)$ in adult mammals of different body mass $\left(\mathrm{m}_{\mathrm{b}}\right)$.

Body mass, oxygen diffusion capacity and maximum metabolic rate values from (1) Gehr et al. 1981; (2) Gehr et al. 1980; (3) Sparti 1992; (4) Canals et al. 2005; (5) Figueroa et al. 2007; (6) Weibel et al. 2004; (7) Bozinovic \& Rosenmann 1989.

\begin{tabular}{|c|c|c|c|c|c|c|}
\hline Family & Species & $\mathrm{Mb}(\mathrm{g})$ & $\mathrm{VO}_{2 \max }(\mathrm{mlO} 2 / \mathrm{gh})$ & $\begin{array}{c}\mathrm{D}_{\mathrm{L}} \mathrm{O}_{2} / \mathrm{m}_{\mathrm{b}} \\
\left(\mathrm{MlO}_{2} / \mathrm{sPag}\right) \times 10^{-7}\end{array}$ & $\Delta \mathrm{PO}_{2}(\mathrm{kPa})$ & SF \\
\hline Soricidae & Suncus etruscus & 2.6 & $34.2_{(2)}$ & $6.92_{(1)}$ & 13.7 & 0.54 \\
\hline Soricidae & Sorex minutus & 2.9 & $28.7_{(3)}$ & $6.55_{(1)}$ & 12.2 & 0.61 \\
\hline Soricidae & Crocidura juvenata & 7 & $15.3_{(3)}$ & $4.00_{(1)}$ & 10.6 & 0.70 \\
\hline Molossidae & Tadarida brasiliensis & 11.25 & $22.3_{(4)}$ & $6.39_{(4)}$ & 9.7 & 0.78 \\
\hline Soricidae & Crocidura russula & 12.2 & $17.4_{(3)}$ & $4.34_{(1)}$ & 11.1 & 0.67 \\
\hline Soricidae & Neomys fodiens & 17 & $17.5_{(3)}$ & $5.65_{(1)}$ & 8.6 & 0.87 \\
\hline Soricidae & Crocidura poennis & 17 & $9.5_{(3)}$ & $3.82_{(1)}$ & 6.9 & 1.09 \\
\hline Muridae & Abrothrix andinus & 25.5 & $15.6_{(4)}$ & $3.59_{(4)}$ & 12.0 & 0.62 \\
\hline Muridae & Abrothrix olivaceus & 26.3 & $12.3_{(4)}$ & $2.56_{(4)}$ & 13.4 & 0.56 \\
\hline Muridae & Mus musculus & 42 & $13.8_{(6)}$ & $5.07_{(1)}$ & 7.6 & 0.99 \\
\hline Muridae & Phyllotis darwini & 75 & $6.9_{(7)}$ & $6.26_{(5)}$ & 3.1 & 2.45 \\
\hline Cavidae & Cavia porcellus & 429 & $3.7_{(6)}$ & $4.17_{(1)}$ & 2.4 & 3.08 \\
\hline Viverridae & Helogale pervula & 429.5 & $7.6_{(1)}$ & $6.52_{(1)}$ & 2.9 & 1.78 \\
\hline Viverridae & Mungos mungo & 1140 & $6.9_{(1)}$ & $3.33_{(1)}$ & 5.7 & 1.31 \\
\hline Viverridae & Genetta tigrina & 1372.5 & $6.1_{(1)}$ & $4.99_{(1)}$ & 3.4 & 2.20 \\
\hline Bovidae & Nesotragus moschatus & 3300 & $5.8_{(1)}$ & $4.73_{(1)}$ & 3.4 & 2.21 \\
\hline Bovidae & Madoqua kirkii & 4200 & $3.3_{(1)}$ & $6.88_{(1)}$ & 1.3 & 5.67 \\
\hline Bovidae & Gazella granti & 10100 & $3.2_{(1)}$ & $5.14_{(1)}$ & 1.7 & 4.31 \\
\hline Bovidae & Capra hircus & 19900 & $3.1_{(1)}$ & $5.00_{(1)}$ & 1.8 & 4.15 \\
\hline Bovidae & Ovis aries & 21800 & $2.8_{(1)}$ & $6.67_{(1)}$ & 1.2 & 6.39 \\
\hline Canidae & Canis familiaris & 22300 & $8.9_{(1)}$ & $6.14_{(1)}$ & 4.0 & 1.87 \\
\hline Bovidae & Connochaetes taurinus & 102000 & $2.7_{(1)}$ & $6.11_{(1)}$ & 1.2 & 6.17 \\
\hline Bovidae & Kobus defasa & 109800 & $2.8_{(1)}$ & $6.71_{(1)}$ & 1.2 & 6.39 \\
\hline Bovidae & Bos indicus & 192500 & $1.7_{(1)}$ & $4.16_{(1)}$ & 1.1 & 6.59 \\
\hline Bovidae & Taurotragus oryx & 240000 & $2.1_{(1)}$ & $4.33_{(1)}$ & 1.4 & 5.44 \\
\hline
\end{tabular}

\section{ACKNOWLEDGMENTS}

We thank Lafayette Eaton for useful comments on a previous version of the manuscript. Claudio Veloso and Andres Sazo provided invaluable assistance in the field and the laboratory. Founded by FONDECYT 1040649 grant to MCL.

\section{REFERENCES}

ALEXANDER RMCN (1981) Factor of safety in the structure of animals. Science Progress 67: 109-130.

ALEXANDER RMCN (1997) A theory of mixed chains applied to safety factors in biological systems. J Theor Biol 184: 247-252.
ALEXANDER RMCN (1998) Symmorphosis and safety factors. In WEIBEL ER, CR TAYLOR CR, BOLIS L (eds). Principles of animal design. The optimization and symmorphosis debate.. Cambridge University Press, Cambridge: $28-36$

BACIGALUPE LD, BOZINOVIC F (2002) Design, limitations and sustained metabolic rate: lessons from small mammals. J Exp Biol 205: 2963-2970

BOZINOVIC F, ROSENMANN M, VELOSO C (1988) Termorregulación conductual en Phyllotis darwini (Rodentia: Cricetidae): efecto de la temperatura ambiente, uso de nidos y agrupamiento social sobre el gasto de energía. Rev Chil Hist Nat 61: 81-86

BOZINOVIC F, ROSENMANN M (1989) Maximum metabolic rate of rodents: physiological and ecological consequences on distributional limits. Functional Ecology 3: 173-181.

CANALS M (2002) Optimizacion del diseño de los organismos vivos: geometría y energética de la frontera. In BOZINOVIC F (Eds) Fisiología Ecológica y Evolutiva: Teoría y casos de estudios en 
animales. Ediciones Universidad Católica, Santiago: 101-121

CANALS M, ATALA C, OLIVARES R, GUAJARDO F, FIGUEROA DP, SABAT P, ROSENMANN M (2005) Functional and structural optimization of the respiratory system of the bat Tadarida brasiliensis (Chiroptera, Molossidae): does airway geometry matter? J Exp Biol 208: 3987-3995

CANALS M, DONOSO C, FIGUEROA DP, SABAT P (2007) Pulmonary hematological parameters, energetic flight demands and their correlation with oxygen diffusion capacity in the lungs. Rev Chil Hist Nat 80: 275-284

CANALS M, FIGUEROA DP, MIRANDA JP, SABAT P (2009a) Effects of environmental temperature on oxygen diffusion capacity during post-natal development in the altricial rodent, Phyllotis darwini. Rev Chil Hist Nat 82: 153-162.

CANALS M, FIGUEROA DP, MIRANDA JP, SABAT P (2009b) Effect of gestational and postnatal environmental temperature on metabolic rate in the altricial rodent, Phyllotis darwini J Thermal Biol 34: 310-314.

CHAPPEL MA, BECH C, BUTTEMER WA (1999) The relationship between central and peripheral organ masses to aerobic performance variation in house sparrows. J Exp Biol 202: 2269-2279

DIAMOND JM (1998) Evolution of biological safety factors a cost/benefit analysis. In WEIBEL ER, TAYLOR CR, BOLIS L (Eds) Principles of animal design: The optimization and symmorphosis debate. Cambridge University Press, Cambridge: 21-27

FIGUEROA DP, OLIVARES R, SALABERRY M, SABAT P, CANALS M (2007) Interplay between the morphometry of the lungs and the mode of locomotion in birds and mammals. Biol Res 40: 193-201

GARLAND T (1998) Conceptual and methodological issues in testing the predictions of symmorphosis. In Weibel ER, Taylor CR and Bolis L (Eds) Principles of animal design: The optimization and symmorphosis debate. Cambridge University Press, Cambridge: 40-47

GEHR P, SEHOVIC S, BURRI PH, CLAASSEN H, WEIBEL ER (1980). The lung of shrews: morphometric estimation of the oxygen diffusion capacity. Respir Physiol 44: 61-86

GEHR P, MWANGI DK, AMMANN A, MALOIY GMO, TAYLOR CR, WEIBEL ER (1981) Design of the mammalian respiratory system. V. Scaling morphometric pulmonary diffusing capacity to body mass: wild and domestic mammals. Respir Physiol 44: $61-86$

HAMMOND KA, CHAPPEL MA, CARDULLO RA, LIN RS, JOHNSEN TS (2000) The mechanistic basis of aerobic performance variation in red jungle fowl. J Exp Biol 203: 2053-2064

JONES JH (1998) Symmorphosis and the mammalian respiratoy system: what is optimal design and does it exist? In Weibel ER, Taylor CR and Bolis L (Eds) Principles of animal design: The optimization and symmorphosis debate. Cambridge University Press, Cambridge: $28-36$

KARASOV WH (1986) Energetics, physiology and vertebrate ecology. Trends Ecol Evol 1: 101-104
RUNCIMAN S, SEYMOUR RS, BAUDINETTE RV, PEARSON JT (2005) An allometric study of lung morphology during development in the Australian pelican, Pelecanus conspicillatus, from embryo to adult. Journal of Anatomy 207: 365-380

SEYMOUR RS, RUNCIMAN S, BAUDINETTE RV (2005) Development of maximum metabolic rate and pulmonary diffusing capacity in the super-precocial Australian Brush Turkey Alectura lathami: an allometric and morphometric study. Comp Biochem Physiol-A Epublication, doi: 10.1016/j.cbpa.2006.03.018

SEYMOUR RS, RUNCIMAN S, BAUDINETTE RV, PEARSON JT (2004) Developmental allometry of pulmonary structure and function in the altricial Australian pelican Pelecanus conspicillatus. J Exp Biol 207: $2663-2669$

SPARTI A (1992) Thermogenic capacity of shrews (mammalian, Soricidae) and its relationship with basal metabolism. Physiol Zool 65(1): 77-96

SPEAKMAN JR (2000) The cost of living: field metabolic rate of small mammals. Adv Ecol Res 30: 177-297

TAKEZAWA J, MILLER FJ, O'NEIL JJ (1980) Singlebreath diffussing capacity and lung volumes in small laboratory mammals. J Appl Physiol 48(6): 1052-1059.

TAYLOR CR, WEIBEL ER (1981) Design of the mammalian respiratory system I. Problems and strategy. Respir Physiol 44: 1-10

TAYLOR CR, WEIBEL ER, WEBER JM, VOCK R, HOPPELER H, ROBERTS TJ, BRICHON G (1996) Design of the oxygen and substrate pathways I. model and strategy to test symmorphosis in a network structure. J Exp Biol 199: 1643-1649

WEIBEL ER, TAYLOR CR, HOPPELER H (1991) The concept of symmorphosis: a testable hypothesis of structure function relationship. Proc Nat Acad Sci 88: 10357-10361

WEIBEL ER, TAYLOR CR, HOPPELER H (1992) Variation in function and design: testing symmorphosis in the respiratory system. Respir Physiol 87: 325-348

WEIBEL ER, TAYLOR CR, WEBER JM, ROBERTS R, HOPPELER H (1996) Design of the oxygen and substrate pathways. VII. Different structural limits for oxygen and substrate supply to muscle and mitochondria. J Exp Biol 199: 1699-1709

WEIBEL ER, TAYLOR CR, BOLIS L (1998) Principles of animal design. The optimization and symmorphosis debate. Cambridge University Press, Cambridge.

WEIBEL ER (1983) Is the lung built reasonably? Am Rev Respir Dis 128: 752-780

WEIBEL ER (1998) Symmorphosis and optimization of biological design: introduction and questions. In: WEIBEL ER, TAYLOR CR, BOLIS L (eds) Principles of animal design. The optimization and symmorphosis debate. Cambridge University Press, Cambridge, pp 112

WEIBEL ER, BACIGALUPE LD, SCHMITT B, HOPPELER H (2004) Allometric scaling of maximal metabolic rate in mammals: muscle aerobic capacity as determinant factor. Respir Physiol Neurobiol 140: 115132

WEINER J (1992) Physiological limit to sustainable energy budgets in bird and mammals: ecological implications. Trends Ecol Evol 7: 384-388 
